\title{
An Improved Mathematical Model for Geological Analysis of Debris Flow
}

\author{
Wu Hengbin ${ }^{1,2,3} \&$ He Siming ${ }^{1,2}$ \\ ${ }^{1}$ Key laboratory of Mountain Hazards and Surface Process, Chinese Academy of Science, 610041, China \\ ${ }^{2}$ Institute of Mountain Hazards and Environment, Chinese Academy of Sciences, 610041, China \\ ${ }^{3}$ Graduate University of Chinese Academy of Sciences, 100049, China \\ Correspondence: He Siming, Key laboratory of Mountain Hazards and Surface Process, Chinese Academy of \\ Science, 610041, China. E-mail: hbw8456@163.com
}

Received: December 9, 2013 Accepted: December 23, 2013 Online Published: February 23, 2014

doi:10.5539/jgg.v6n1p129 URL: http://dx.doi.org/10.5539/jgg.v6n1p129

\begin{abstract}
Based on computational fluid dynamics, the debris flow is considered as a one-dimensional, laminar, unsteady flow down a steep slope with Herschel-Bulkley rheological model, and the conservation of mass and momentum are integrated along the depth of plug zone and shear zone, respectively. In addition, the mathematical model is improved by analyzing the mainly influencing factors of debris flow and adding the drag force and earth pressure coefficient into the depth-averaged equations. The Lagrange difference method is used to solve the partial differential equations in this paper. the model can reproduce the motion of debris flow with a level of accuracy by comparing the results of two simple cases.
\end{abstract}

Keywords: debris flow, runout analysis, mudflow, depth-averaged equations

\section{Introduction}

In mountain regions of western China, landslide, debris avalanche, and debris flow frequently occur and cause serious damages, especially after May 12 , Wenchuan earthquake. The forecasting, warning and risk management of debris flow hazards are especially important for disaster prevention and reduction, and the related studies are mainly focused on empirical method, lump method, continuum method, and distinct element method.

For the empirical method, it is influenced by the external factors such as grain composition of debris flow and topography and cannot obtain the velocity and deposition of debris flow with the change of time. The continuum method and distinct element method are all built in the mathematical equations of the motion of debris flow with different assumptions. The continuum method is based on computational fluid dynamics and mainly divided into two approaches.

For the first approach, because the length of debris flow is significantly larger than its height, the three-dimensional Navier-Stokes equations can be simplified to a set of two-dimensional equations by considering vertically averaged quantities (Gessese et al., 2012), and the depth-integrated method is widely used to simulate the motion of landslide, flow slide and debris flow (Hungr, 1995; Hungr et al., 2008; 2009; Iverson, 1997; Savege \& Hutter, 1989). The other approach is based on the full Navier-Stokes equations (incompressible flow), the interface tracking method will be used to describe the interface distribution and motion characteristics. Different numerical models are conducted to simulate the dam-break problem (Biscarini et al., 2010), landslide runout (Vassilevski et al., 2012), landslide generated water waves (Biscarini, 2010) and snow avalanche impacting barriers (Dutykh et al., 2011). The second approach is similar to the shallow water equation, which is widely used to simulate the dam break and flood disasters and many achievements have been obtained in the numerical simulations and experiments (Xu et al., 2012; 2013; Maleewong, 2011).

Debris flow is considered as a two two-dimensional, laminar, non- hydroplaning muddy flows resulting from submarine slides that occur in deep waters, and can be approximated as Bingham fluids (Huang et al., 1997; 1999; Balmforth et al., 1999). Jiang et al. (1993) present a numerical model that simulates the coupling of a Bingham plastic mudslide on a gentle uniform slope with the surface waves which it generates. An asymptotic solution for the flow of a Bingham fluid along a two-dimensional channel of slowly varying width is developed by Frigaard and Ryan (2004). 
The Bingham model cannot exhibit the non-linear property of debris flow, the Herschel-Bulkley model is studied, which is a generalized non-Newtonian fluid. The 1D numerical model of the down slope flow and deposition of muddy subaqueous debris flow is presented by incorporating the Herschel-Bulkley and bilinear model (Imran et al., 2001). A matched-asymptotic perturbation method is implemented analytically told get asymptotic solution for both the outer region away from, and the inner region near, the wave front by applying von Karman momentum integral method (Huang \& Garcia, 1998).

The present models mentioned above cannot express the friction property and earth pressure coefficient of debris flow that is important for simulating its motion. In this paper, based on the boundary layer approximation method, combined the Herschel-Bulkley rheological model, the mathematical equations are shown in section 2; the BVP model is introduced, and an improved mathematical model is provided in section 3; the solution method and results analysis are made in section 4 and section 5 , respectively.

\section{Mathematical Model}

The debris flow is considered as a two-dimensional, unsteady, laminar flow down a relatively steep slope at an angle $\theta$, and a coordinate system is defined as the x-axis down slope and the $y$-axis upward normal to the bed. Based on the boundary layer approximation, the governing equation of debris flow can be written as,

$$
\begin{gathered}
\frac{\partial u}{\partial x}+\frac{\partial v}{\partial y}=0 \\
\frac{\partial u}{\partial t}+u \frac{\partial u}{\partial x}+v \frac{\partial v}{\partial y}=\frac{1}{\rho}\left(-\frac{\partial P}{\partial x}+\frac{\partial \tau}{\partial y}\right)+g \sin \theta \\
0=-\frac{1}{\rho}\left(\frac{\partial P}{\partial y}\right)-g \cos \theta
\end{gathered}
$$

Where $u, v$ are the $\mathrm{x} ; \mathrm{y}$ directional velocities, respectively. $P, \tau$ are the pressure and shear stress, respectively. $\rho$ is the density, and $\theta$ is the angle of slope.

From Equations (1-3), the pressure can be obtained as hydrostatic,

$$
P=\rho g \cos \theta(h-y)
$$

If the height $\mathrm{y}$ equal zero, the bed can be considered as fixed boundary condition, the velocities of $\mathrm{x}$ and $\mathrm{y}$ direction are zero. $u, v=0$, at $y=0$. While the free surface condition is considered when the height $\mathrm{y}$ equal $\mathrm{h}$, the pressure and shear stress can be set as zero. $P, \tau=0$, at $y=h$.

We can think the material derivation is zero at the free surface,

$$
v=\frac{\partial h}{\partial t}+u \frac{\partial h}{\partial x}, \text { at } y=h
$$

The Herschel-Bulkley rheological model exhibits a non-linear property and is widely used to simulate the motion of mudflow, debris flow, debris avalanche and flow slide. The rheological model can be expressed as,

$$
\left|\frac{\gamma}{\gamma_{r}}\right|^{n}= \begin{cases}0 & \text { for }|\tau| \leq \tau_{y} \\ \frac{\tau}{\tau_{y} \operatorname{sgn}(\gamma)} & \text { for }|\tau|>\tau_{y}\end{cases}
$$

Here, $\gamma$ is the shear strain rate, $\gamma_{r}=\left(\tau_{y} / K\right)^{1 / n}$, where $\tau_{y}$ is the yield stress, $\mathrm{K}, \mathrm{n}$ are empirical parameters, respectively.

For the Bingham and Herschel-Bulkley fluid, the flowing fluid can be divided into two layer, the plug layer and shear layer. For the plug layer, the velocity gradient can be considered as zero. In the interface between plug layer and shear layer, the shear stress equal yield stress.

$$
\tau=\tau_{y}, \text { at } y=h_{s}
$$

Where the height of shear zone of debris flow $h_{s}=h-h_{p}$, here $h_{\mathrm{p}}$ is the height of plug zone of debris flow. Combined the boundary conditions, substituting the rheological model into the governing equation, the velocity is integrated, we can obtain, 


$$
u(y)= \begin{cases}u_{p} & \text { for } y \geq h_{s} \\ \left(\frac{\rho g \sin \beta}{K}\right)^{1 / n} \frac{1}{1+1 / n}\left(h_{s}^{1+1 / n}-\left(h_{s}-y\right)^{1+1 / n}\right) & \text { for } y<h_{s}\end{cases}
$$

Here, the velocity of plug zone of debris flow $u_{p}=\left(\frac{\rho g \sin \beta}{K}\right)^{1 / n} \frac{1}{1+1 / n} h_{s}^{1+1 / n}$.

The depth-integrated velocity is also written as,

$$
\bar{u}=h^{-1} \int_{0}^{h} u d y=u_{p}\left(1-\frac{n h_{s}}{h(2 n+1)}\right)
$$

Differentiating Equation (8) at $\mathrm{y}=0$ and use of $\mathrm{u}_{\mathrm{p}}$ yields,

$$
\left(\frac{\partial u}{\partial y}\right)_{y=0}=\frac{n+1}{n} \frac{(2 n+1) u_{h}}{(2 n+1) h h_{s}-n h_{s}^{2}}
$$

Substituting Equation (10) into Equation (6), we can obtain the shear stress at the base,

$$
\tau_{b}=\left(\tau_{y}+K\left|\frac{(n+1) u_{p}}{n h_{s}}\right|\right) \operatorname{sgn}\left(u_{p}\right)
$$

When the $\mathrm{n}$ equal 1 , the model can be reduced into Bingham model,

$$
u(y)= \begin{cases}u_{p} & \text { for } y \geq h_{s} \\ \frac{\rho g \sin \beta}{K}\left(h_{s} y-h_{s}^{2} / 2\right) & \text { for } y<h_{s}\end{cases}
$$

Here, $u_{p}=\frac{\tau_{y}}{K}\left(h-\frac{3}{2} \frac{\tau_{y}}{\rho g \sin \beta}\right)$.

Based on the boundary layer theory, the Von Karman momentum integral method and Leibniz rule are used to integrate the Equation (1) from 0 to $h_{s}$, we can obtain,

$$
\frac{\partial h}{\partial t}+\frac{\partial h u}{\partial x}=0
$$

The similar to Equation (13), the Equations (2) and (3) can be integrated from 0 to $h_{\mathrm{S}}$ and from 0 to $\mathrm{h}$, we can obtain the momentum equations of plug layer and shear layer,

The momentum equation of plug layer,

$$
\frac{d u_{p}}{d t}=\left(u-u_{p}\right) \frac{\partial u_{p}}{\partial x}-g \Delta \rho \cos \theta \frac{\partial h}{\partial x}+g \Delta \rho \sin \theta-\frac{\tau_{y}}{\rho_{d} h_{p}} \operatorname{sgn}\left(u_{p}\right)
$$

The momentum equation of shear layer,

$$
\begin{aligned}
\frac{d u}{d t}=\frac{1}{h} \frac{\partial}{\partial x}\left(h u^{2}+\right. & \left.\beta_{1} h u_{p}^{2}-\left(1+\beta_{1}\right) h u u_{p}\right)+\Delta \rho g \sin \theta-\Delta \rho g \cos \theta \frac{\partial h}{\partial x} \\
& -\frac{\tau_{y}}{\rho h} \operatorname{sgn}\left(u_{p}\right)-\frac{\beta \tau_{y}}{\rho h}\left|\frac{u_{p}}{\gamma_{r} h_{s}}\right|^{n} \operatorname{sgn}\left(u_{p}\right)
\end{aligned}
$$

Where $\mathrm{h} ; \mathrm{h}_{\mathrm{s}} ; \mathrm{u} ; \mathrm{u}_{\mathrm{p}}$ are the height, plug layer height, velocity and plug layer velocity, respectively. $\operatorname{sgn}(u)=|u| / u, \Delta \rho=\left(\rho-\rho_{a}\right) / \rho$, where $\rho_{a}$ is the density of upper fluid(air or water). $\frac{d}{d t}=\frac{\partial}{\partial t}+u \frac{\partial}{\partial x}$, $u=u_{p}\left(h_{p}+\alpha_{1} h_{s}\right) / h$.

The coefficients in Equations (14) and (15) are,

$$
\begin{gathered}
\alpha_{1}=\frac{1}{u_{p} h_{s}}=\int_{0}^{h_{s}} u(y) d y=\frac{1+1 / n}{2+1 / n} \\
\alpha_{2}=\frac{1}{u_{p}^{2} h_{s}}=\int_{0}^{h_{s}} u^{2}(y) d y=1-\frac{2}{2+1 / n}+\frac{1}{3+2 / n}
\end{gathered}
$$




$$
\begin{gathered}
\beta=(1+1 / n)^{n} \\
\beta_{1}=\left(\alpha_{1}-\alpha_{2}\right) /\left(1-\alpha_{1}\right)
\end{gathered}
$$

\subsection{An Improved Model}

The rheological model is very important for simulating the motion of debris flow, the Herschel-Bulkley model cannot consider the pore pressure and Mohr-Coulomb properties, and the parameters are difficult to be measured. $\mathrm{Wu}$ et al. (2013) propose an improved rheological to simulate the motion of flow slide and debris flow based on Herschel-Bulkley model, Mohr-Coulomb criterion, and Bi-viscous model and is written as follow,

$$
\tau= \begin{cases}\eta_{0} \dot{\gamma} & \text { for }|\tau| \leq \tau_{0} \\ c+p \tan \phi_{a}+K\left(\dot{\gamma}-\left(c+p \tan \phi_{a}\right) / \eta_{0}\right)^{m} & \text { for }|\tau|>\tau_{0}\end{cases}
$$

Where $\phi_{a}$ is the apparent friction angle, and can be defined by $\sigma_{n} \tan \phi_{a} \approx\left(\sigma_{n}-p_{u}\right) \tan \phi ; \mathrm{p}$ is the hydrostatic pressure, $\eta_{0}$ is the initial viscosity of debris flow.

To simplify the complexity of formula derivation, the BVP model can be reduced as follows,

$$
\tau= \begin{cases}\eta_{0} \dot{\gamma} & \text { for }|\tau| \leq \tau_{0} \\ c+p \tan \phi_{a}+K(\dot{\gamma})^{m} & \text { for }|\tau|>\tau_{0}\end{cases}
$$

The deformation of Equation (17) become,

$$
\left|\frac{\gamma}{\gamma_{r}}\right|^{n}= \begin{cases}0 & \text { for }|\tau| \leq \tau_{y} \\ \frac{\tau}{\left(c+p \tan \phi_{a}\right) \operatorname{sgn}(\gamma)} & \text { for }|\tau|>\tau_{y}\end{cases}
$$

Here $\gamma_{r}=\left(\left(c+p \tan \phi_{a}\right) / K\right)^{1 / n}$.

From Equations (6) and (18), it can be seen that the difference between the BVP model and the Herschel-Bulkley model is the shear stress item; we can substitute the shear stress $\tau_{y}=c+p \tan \phi_{a}$ into the Equations (13)-(15). It is worth noting that the approximation value of pressure is set as $p=\Delta \rho g h_{p} \cos \theta$.

For the subaqueous debris flow, the drag force of water cannot be ignored, and for Bingham model, the shear stress is depth integrated from 0 to $\mathrm{h}$,

$$
\frac{1}{\rho} \int_{0}^{h} \frac{\partial \tau}{\partial y} d y=\frac{1}{\rho}\left(\tau_{\text {top }}-\tau_{\text {bottom }}\right) \approx \frac{1}{\rho}\left(\tau_{\text {drag }}-\tau_{y}-2 \mu \frac{u_{p}}{h}\right)
$$

To simplify the problem, the drag force can be added into the shear stress, and the signs of drag force are noteworthy.

The drag force is written as,

$$
\tau_{d r a g}=-0.5 \rho_{a} C_{S F} u^{2}
$$

Where $C_{S F}$ is set as 2e-3 in this paper for simplifying the problems.

The similar to drag force, for Bingham model, the earth pressure is depth integrated from 0 to $\mathrm{h}$,

$$
\frac{1}{\rho} \int_{0}^{h} \frac{\partial p}{\partial x} d y=\frac{\rho g \cos \theta}{\rho} \int_{0}^{h} \frac{\partial h-y}{\partial x} d y \approx-g \cos \theta h \frac{\partial h}{\partial x}
$$

The right side of Equation (21) can written as follow due to the existence of lateral earth pressure, $-g \cos \theta h k_{a c t / p a s s} \frac{\partial h}{\partial x}$, and the Equation (21) become,

$$
\frac{1}{\rho} \int_{0}^{h} \frac{\partial p}{\partial x} d y=\frac{\rho g \cos \theta}{\rho} \int_{0}^{h} \frac{\partial h-y}{\partial x} d y \approx-g \cos \theta h k_{a c t / p a s s} \frac{\partial h}{\partial x}
$$

Where 


$$
\begin{gathered}
k_{\text {act } / \text { pass }}= \begin{cases}k_{\text {active }} & \text { if } \partial u / \partial x>\xi \\
1 & \text { if }|\partial u / \partial x| \leq \xi \\
k_{\text {passive }} & \text { if } \partial u / \partial x<\xi\end{cases} \\
k_{\text {act } / \text { pass }}=2\left(1 \mp \sqrt{1-\left(1+\tan ^{2} \theta\right) \cos ^{2} \phi} / \cos ^{2} \phi-1\right.
\end{gathered}
$$

To prevent the mathematical logic error, $\xi$ is set in the model and its value is very small.

Combined the BVP model, considering the drag force and earth pressure coefficient, substituting Equations (18), (20) and (23) into Equations (1), (2) and (3), the governing equations become,

Mass equation,

$$
\frac{\partial h}{\partial t}+\frac{\partial h u}{\partial x}=0
$$

The momentum equation of plug player,

$$
\begin{aligned}
\frac{d u_{p}}{d t} & =\left(u-u_{p}\right) \frac{\partial u_{p}}{\partial x}-g \Delta \rho \cos \theta \frac{\partial h}{\partial x}+g \Delta \rho \sin \theta \\
& -\frac{c+\Delta \rho g h_{p} \cos \theta \tan \phi_{a}+0.5 \rho_{a} C_{S F} u^{2}}{\rho_{d} h_{p}} \operatorname{sgn}\left(u_{p}\right)
\end{aligned}
$$

The momentum equation of shear player,

$$
\begin{gathered}
\frac{d u}{d t}=\frac{1}{h} \frac{\partial}{\partial x}\left(h u^{2}+\beta_{1} h u_{p}^{2}-\left(1+\beta_{1}\right) h u u_{p}\right)+\Delta \rho g \sin \theta-k_{\text {act } / p a s s} \Delta \rho g \cos \theta \frac{\partial h}{\partial x} \\
-\frac{c+\Delta \rho g h_{p} \cos \theta \tan \phi_{a}+0.5 \rho_{a} C_{S F} u^{2}}{\rho h}\left(1+\left|\frac{u_{p}}{\gamma_{r} h_{s}}\right|^{n}\right) \operatorname{sgn}\left(u_{p}\right)
\end{gathered}
$$

From Equations (24)-(26), it can be seen that the mass change over time depends on the spatial variation of $x$ directional mass fluxes, which is same as shallow water equation.

For the momentum equation, the acceleration of debris flow depends on the following factors, (1) the spatial variation of $\mathrm{x}$ momentum fluxes; (2) driving gravitational force; (3) dissipative internal friction force; and (4) dissipative basal friction force, its direction depends on the velocity of debris flow. For the Herschel-Bulkley model, the cohesion and internal friction angle cannot be considered and the yield stress is difficult to be measured. The BVP model is introduced for overcome the shortcomings of the Herschel-Bulkley model. For the subaqueous debris flow, the drag force is very important, which can be added into the shear stress item. In addition, in the plug layer, the velocity gradient of debris flow is zero, the earth pressure coefficient could not be considered, which it is not reasonable in shear layer. So, the earth pressure coefficient $k_{\text {act=pass }}$ is added into the internal friction force item.

\subsection{Solution Method}

The Lagrange finite difference method is used to solve the governing equations in this paper. The debris flow is divided into a number of cells, and the index $i$ and $j$ are denoted as the cell centers and cell boundary points, respectively. The mass conservation can be written as,

$$
\int_{x_{j}}^{x_{j+1}} h d x=D_{i}\left(x_{j+1}-x_{j}\right)=\text { const }
$$

The difference equations of momentum conservation of plug layer is,

$$
u_{p j}^{t+\Delta t}=u_{p j}^{t}+\Delta t\left(\left(u-u_{p}\right) \frac{\partial u_{p}}{\partial x}-g \Delta \rho \cos \theta \frac{\partial h}{\partial x}+g \Delta \rho \sin \theta-\frac{\tau_{y}}{\rho_{d} h_{p}} \operatorname{sgn}\left(u_{p}\right)\right)
$$


and the shear layer is also obtained as,

$$
\begin{gathered}
u_{j}^{t+\Delta t}=u_{j}^{t}+\Delta t\left(\frac{1}{h} \frac{\partial}{\partial x}\left(h u^{2}+\beta_{1} h u_{p}^{2}-\left(1+\beta_{1}\right) h u u_{p}\right)+\Delta \rho g \sin \theta-k_{a c t / p a s s} \Delta \rho g \cos \theta \frac{\partial h}{\partial x}\right. \\
\left.-\frac{c+\Delta \rho g h_{p} \cos \theta \tan \phi_{a}+0.5 \rho_{a} C_{S F} u^{2}}{\rho h}\left(1+\left|\frac{u_{p}}{\gamma_{r} h_{s}}\right|^{n}\right) \operatorname{sgn}\left(u_{p}\right)\right)
\end{gathered}
$$

The velocities of nodes are,

$$
\left\{\begin{array}{l}
u_{j}=u_{j}+v_{m}\left(u_{j+1}-2 u_{j}+u_{j-1}\right) \\
u_{p j}=u_{p j}+v_{m}\left(u_{p j+1}-2 u_{p j}+u_{p j-1}\right)
\end{array}\right.
$$

Here, $v_{m}=v_{c} \frac{h_{j+1}-2 h_{j}+h_{j-1}}{h_{j+1}-2 h_{j}+h_{j-1}}$, where $\mathrm{v}_{\mathrm{c}}$ is artificial viscosity item, and its value could set as 0.01-0.03.

\section{Results Analysis}

The initial shape of debris flow has a thickness $D_{i}$, which varies in the shape of a parabola with length $\mathrm{L}$ and maximum height $D_{0}$, the initial shape of debris flow is shown in Figure 1 and is set as follows by Jiang and LeBlond (1993).

$$
\frac{D_{i}}{D_{0}}=1-4\left[\left(\frac{x-L / 2}{L}\right)^{2}\right]
$$

The maximum height and length of debris flow are set as $24 \mathrm{~m}$ and $600 \mathrm{~m}$, respectively. The tangent of the plane inclined angle is 0.05 , and the length of inclined plane is $5000 \mathrm{~m}$. In the numerical model, the mesh size of debris flow is $1.0 \mathrm{~m}$, the density of debris flow and air are $1.5 \mathrm{t} / \mathrm{m} 3$ and $1 \mathrm{~kg} / \mathrm{m} 3$, respectively. $A$ is the area of element, $u$ is the average velocity, the step size of time is $0.001 \sqrt{\Delta x / 9.81}$. Calculation stops if the velocity of the front of debris flow is less than $0.1 \mathrm{~m} / \mathrm{s}$.

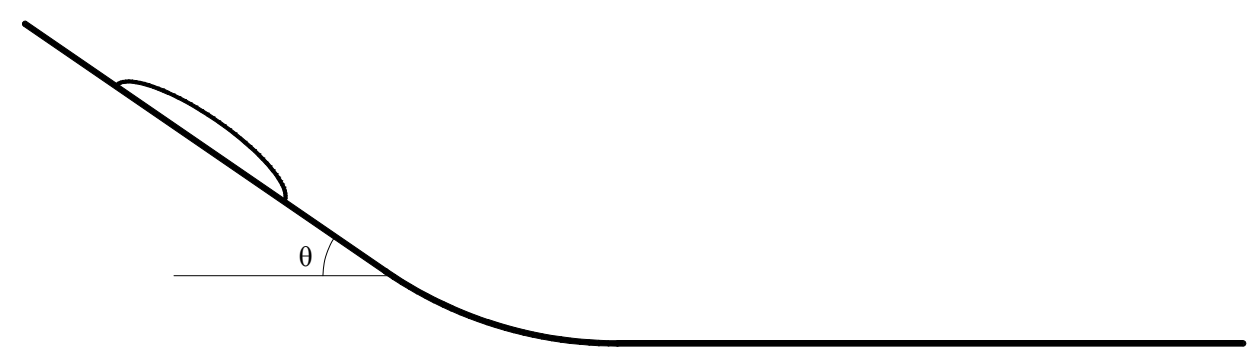

Figure 1. Numerical model of debris flow

Two cases are performed to simulate the motion of debris flow, and the numerical model is shown in Figure 3. For the first case, the cohesion and apparent friction angle are set as $1000 \mathrm{~Pa}$, and 22 degree, respectively. The simulated results are shown in Figures 2-4. Figure 2 is the motion of debris flow, and indicates that the velocity of debris flow is increasing due to the gravitational force at the beginning of time, and forms a surge in front. While it is decreasing after 4 minutes because the basal friction force and internal friction force are increased, and the surge is not obvious. Combined Figure 3, the velocity of debris flow, we can obtain that the velocity of debris flow is fast in 1 minute, start falling after 2 minutes, and then the falling speed significantly slow down. The velocity of the front of debris flow is shown in Figure 4, from Figure 4, it can be seen that the velocity increases rapidly in the beginning, decreases after reaching the peak value, and the falling speed significantly slow down, which the law is similar to Figure 3. 


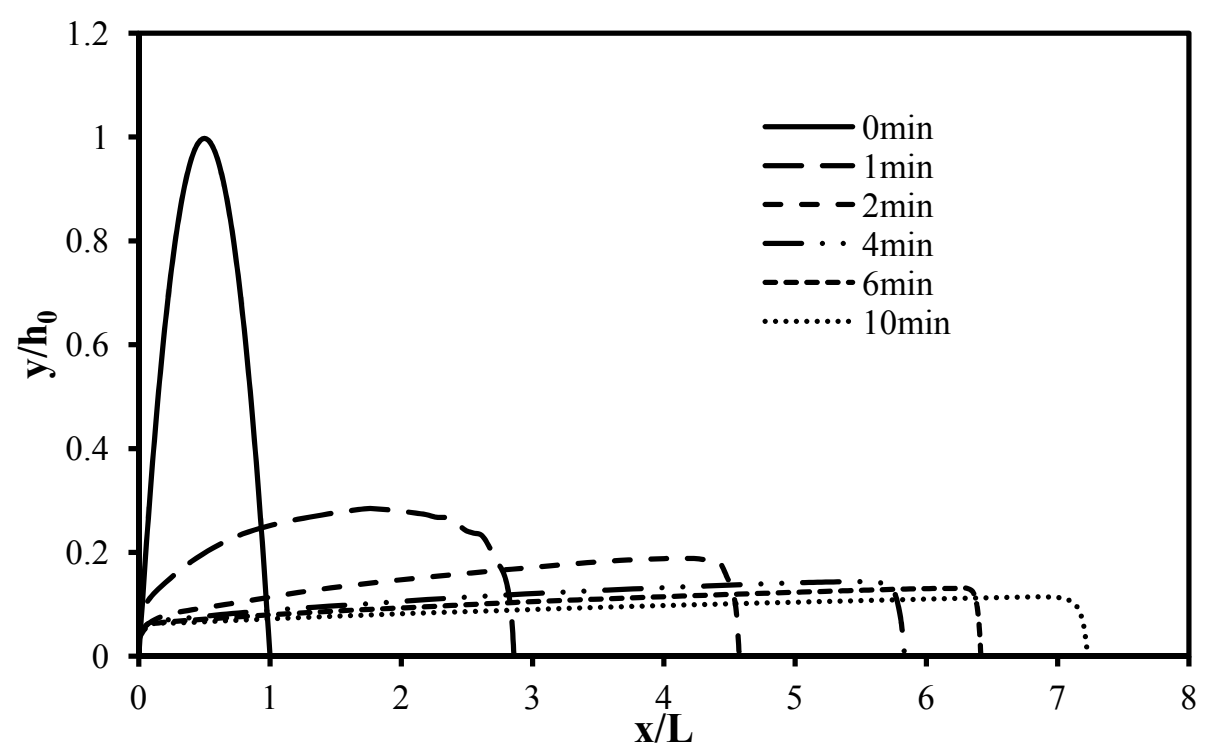

Figure 2. The motion of debris flow ( $\mathrm{c}=1000 \mathrm{~Pa}, \theta=22)$

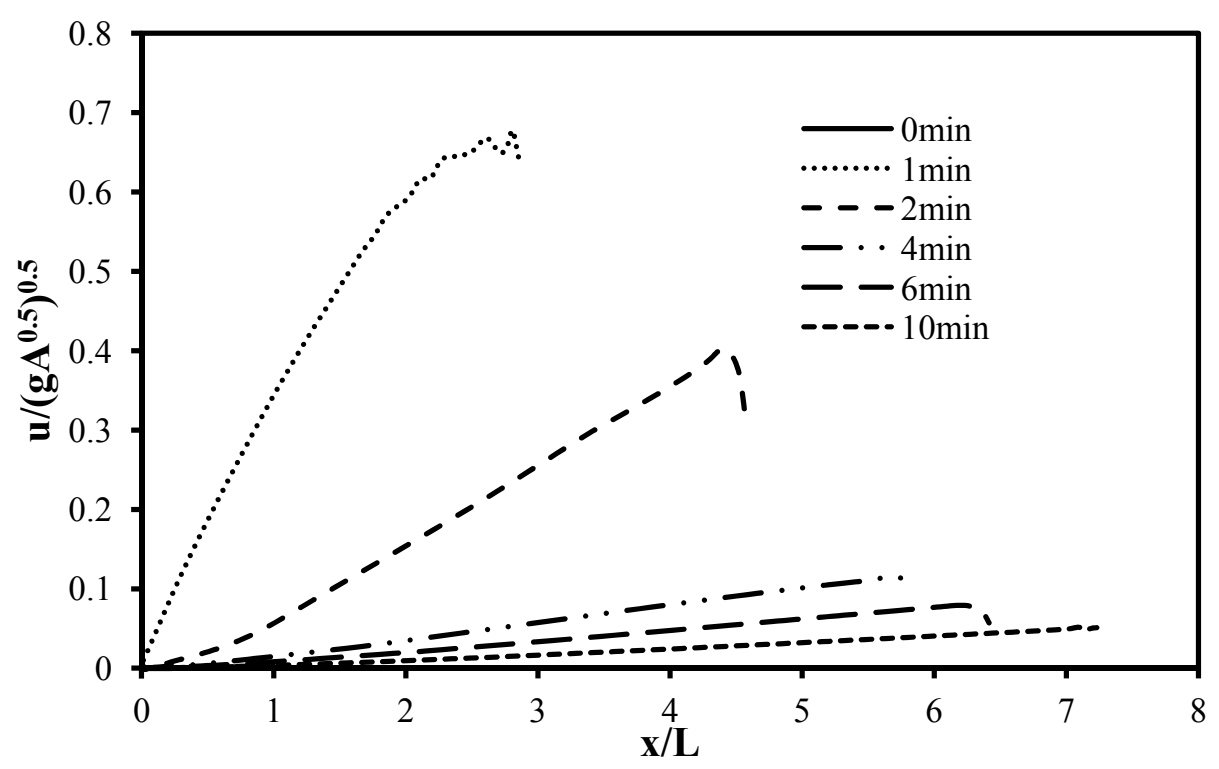

Figure 3. The velocities of debris flow $(\mathrm{c}=1000 \mathrm{~Pa}, \theta=22)$ 


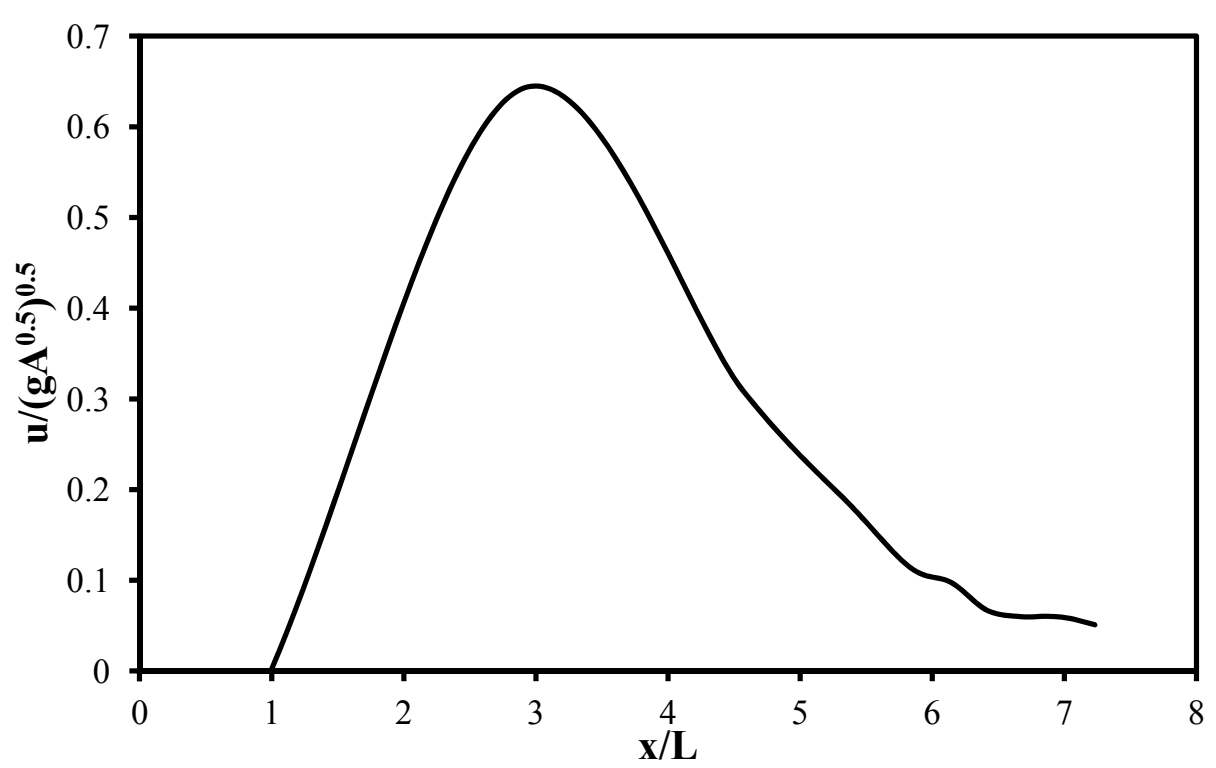

Figure 4. The velocities of the front of debris flow $(\mathrm{c}=1000 \mathrm{~Pa}, \theta=22)$

For the second case, the cohesion and apparent friction angle are set as $500 \mathrm{~Pa}$, and 15 degree, respectively. The motion of debris flow is shown in Figure 5, compared with Figure 4, the velocity of debris flow is more faster than the first case; the moving distance of debris flow reaches 5.6 times its length in two minutes, while the first cases is 4.6 times; when the velocity of debris flow trends zero, the moving distance of debris flow reaches 14 times its length, and the first case is 7 times. It worth noting that, the front velocities of debris flow are nearly for the two cases, and its value range 0.6-0.7.

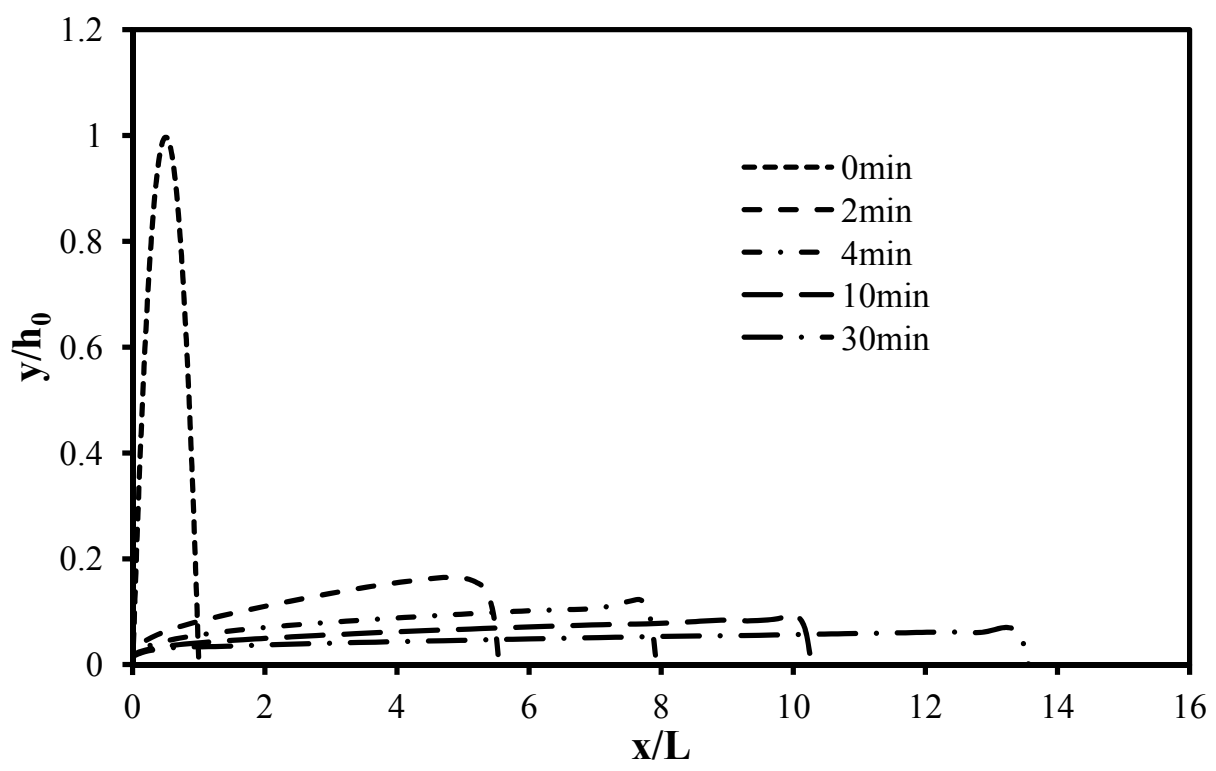

Figure 5. The motion of debris flow $(\mathrm{c}=500 \mathrm{~Pa}, \theta=15)$ 


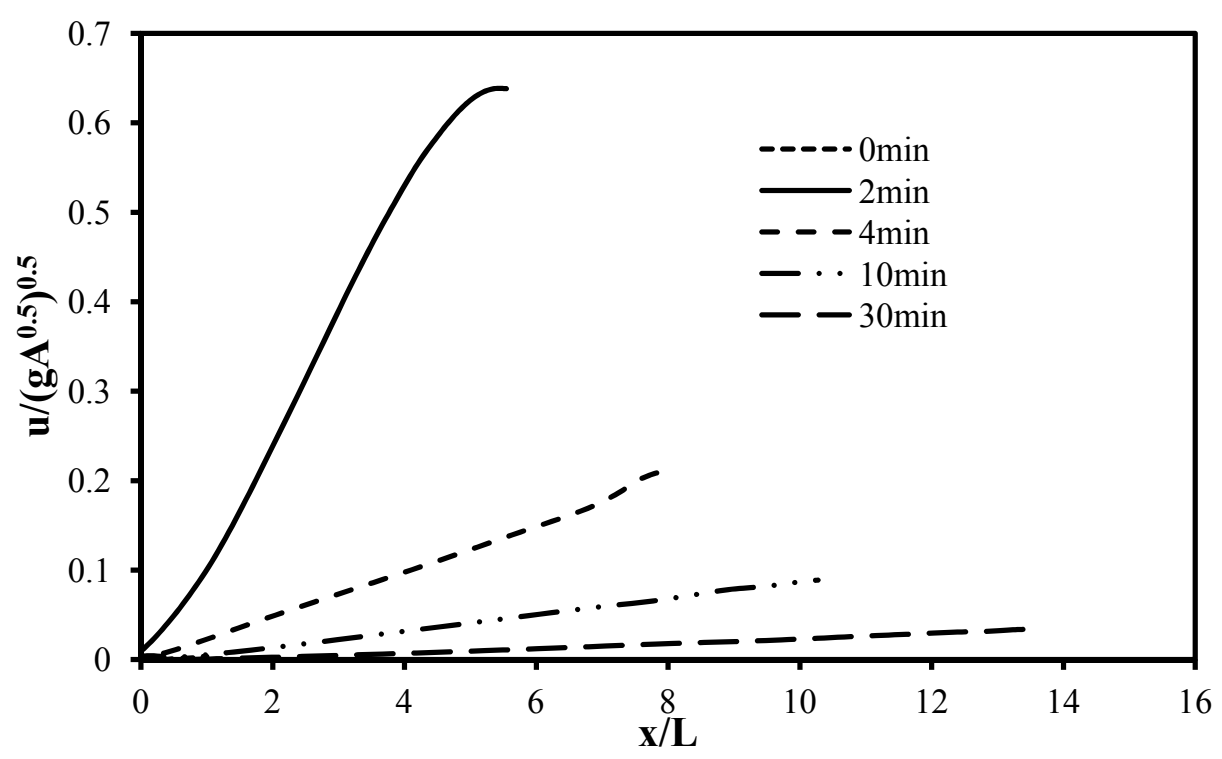

Figure 6. The velocities of debris flow (c $=500 \mathrm{~Pa}, \theta=15)$

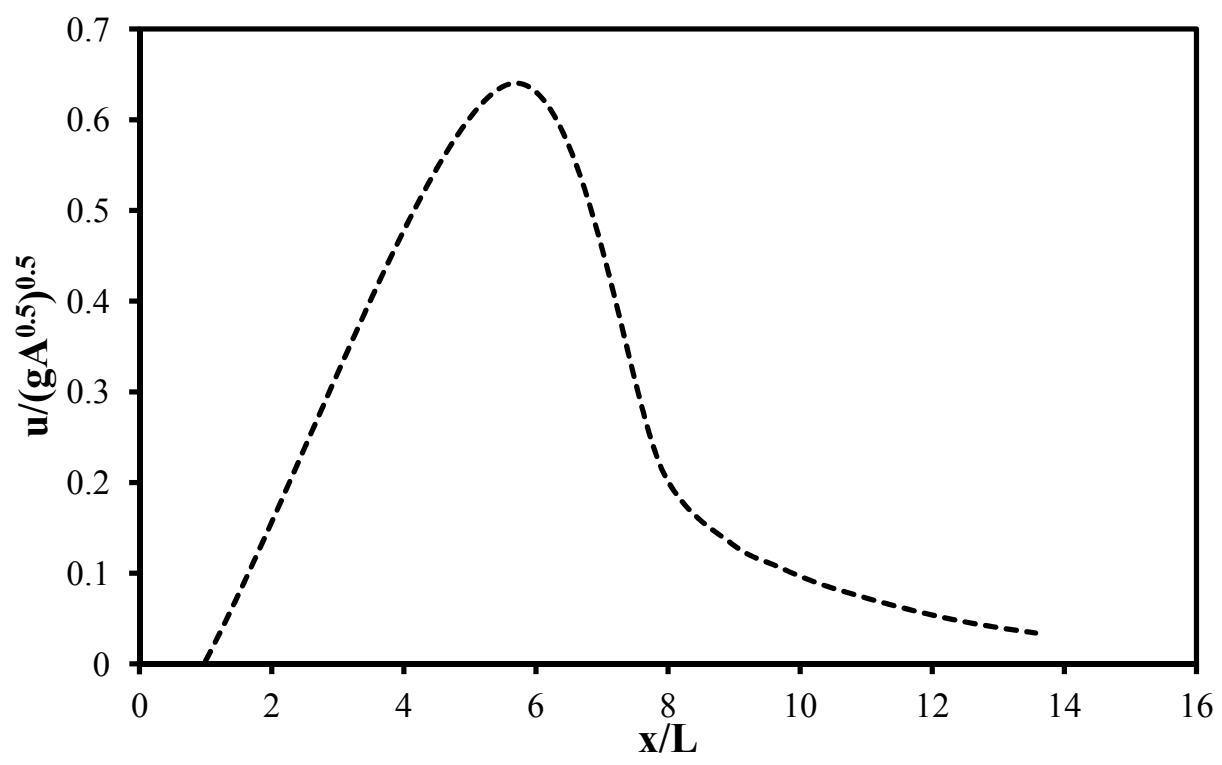

Figure 7. The velocities of the front of debris flow ( $\mathrm{c}=500 \mathrm{~Pa}, \theta=15)$

\section{Conclusions}

Based on the Herschel-Bulkley model, by analyzing the mainly influencing factors of debris flow, the BVP rheological model is introduced, the governing equations of debris flow are improved by adding the drag force and earth pressure coefficient into the depth-averaged equations, and the Lagrange difference method is used to simulate the motion of debris flow on the inclined plane. The simulated results show that the model can reproduce the motion of debris flow with a level of accuracy.

There have many problems in the model proposed in this paper, such as, it cannot consider the lateral spreading due to the limit of one dimensional model; the material transfer in the interface between the plug layer and shear layer and the turbulence factor have not yet been considered.

\section{References}

Balmforth, N. J., \& Craster, R. V. (1999). A consistent thin-layer theory for Bingham plastics. Journal of non-newtonian fluid mechanics, 84(1), 65-81. http://dx.doi.org/10.1016/S0377-0257(98)00133-5

Biscarini, C. (2010). Computational fluid dynamics modelling of landslide generated water waves. Landslides, 7(2), 117-124. http://dx.doi.org/10.1007/s10346-009-0194-z

Biscarini, C., Francesco, S. D., \& Manciola, P. (2010). CFD modelling approach for dam break flow studies. 
Hydrology and Earth System Sciences, 14(4), 705-718. http://dx.doi.org/10.5194/hess-14-705-2010

Dutykh, D., Acary - Robert, C., \& Bresch, D. (2011). Mathematical Modeling of Powder - Snow Avalanche Flows. Studies in Applied Mathematics, 127(1), 38-66. http://dx.doi.org/10.1111/j.1467-9590.2010.00511.x

Frigaard, I. A., \& Ryan, D. P. (2004). Flow of a visco-plastic fluid in a channel of slowly varying width. Journal of non-newtonian fluid mechanics, 123(1), 67-83. http://dx.doi.org/10.1016/j.jnnfm.2004.06.011

Gessese, A., \& Sellier, M. (2012). A Direct Solution Approach to the Inverse Shallow-Water Problem. Mathematical Problems in Engineering, 2012. http://dx.doi.org/10.1155/2012/417950

Huang, X., \& Garcia, M. H. (1997). A perturbation solution for Bingham-plastic mudflows. Journal of hydraulic Engineering, 123(11), 986-994. http://dx.doi.org/10.1061/(ASCE)0733-9429(1997)123:11(986)

Huang, X., \& Garcia, M. H. (1998). A Herschel-Bulkley model for mud flow down a slope. Journal of fluid mechanics, 374(1), 305-333. http://dx.doi.org/10.1017/S0022112098002845

Huang, X., \& Garcia, M. H. (1999). Modeling of non-hydroplaning mudflows on continental slopes. Marine Geology, 154(1), 131-142. http://dx.doi.org/10.1016/S0025-3227(98)00108-X

Hungr, O. (1995). A model for the run out analysis of sentence concerning rapid flow slides, debris flows and avalanches. Canadian Geotechnical Journal, 32, 610-623. http://dx.doi.org/10.1139/t95-063

Hungr, O., \& McDougall, S. (2009). Two numerical models for landslide dynamic analysis. Computers \& Geosciences, 35(5), 978-992. http://dx.doi.org/10.1016/j.cageo.2007.12.003

Hungr, O., McDougall, S., Wise, M., \& Cullen, M. (2008). Magnitude-frequency relationships of debris flows and debris avalanches in relation to slope relief. Geomorphology, 96(3), 355-365. http://dx.doi.org/10.1016/j.geomorph.2007.03.020

Imran, J., Parker, G., Locat, J., \& Lee, H. (2001). 1D numerical model of muddy subaqueous and subaerial debris flows. Journal of hydraulic engineering, 127(11), 959-968. http://dx.doi.org/10.1061/(ASCE) 0733-9429(2001)127:11(959)

Iverson, R. M. (1997). The physics of debris flows. Reviews of geophysics, 35(3), $245-296$. http://dx.doi.org/10.1029/97RG00426

Jiang, L., \& LeBlond, P. H. (1993). Numerical modeling of an underwater Bingham plastic mudslide and the waves which it generates. Journal of Geophysical Research: Oceans (1978-2012), 98(C6), 10303-10317. http://dx.doi.org/10.1029/93JC00393

Maleewong, M. (2011). Modified Predictor-Corrector WAF Method for the Shallow Water Equations with Source Terms. Mathematical Problems in Engineering. http://dx.doi.org/10.1155/2011/178491

Savage, S. B., \& Hutter, K. (1989). The motion of a finite mass of granular material down a rough incline. Journal of Fluid Mechanics, 199(1), 177-215. http://dx.doi.org/10.1017/S0022112089000340

Vassilevski, Y. V., Nikitin, K. D., Olshanskii, M. A., \& Terekhov, K. M. (2012). CFD technology for 3D simulation of large-scale hydrodynamic events and disasters. Russian Journal of Numerical Analysis and Mathematical Modelling, 27(4), 399-412. http://dx.doi.org/10.1515/rnam-2012-0022

Wu, H. B., He, S. M., Wang, D. P., \& Zhang, W. C. (2013). Runout and impact analysis of flow slide based on computational fluid dynamics, Electronic Journal of Geotechnical Engineering, 18, 3695-3717.

Xu, F. G., Yang, X. G., Zhou, J. W., \& Hao, M. H. (2013). Experimental Research on the Dam-Break Mechanisms of the Jiadanwan Landslide Dam Triggered by the Wenchuan Earthquake in China. The Scientific World Journal, 2013. http://dx.doi.org/10.1155/2013/272363

Xu, F., Zhou, H., Zhou, J., \& Yang, X. (2012). A Mathematical Model for Forecasting the Dam-Break Flood Routing Process of a Landslide Dam. Mathematical Problems in Engineering. http://dx.doi.org/10.115 $5 / 2012 / 139642$

\section{Copyrights}

Copyright for this article is retained by the author(s), with first publication rights granted to the journal.

This is an open-access article distributed under the terms and conditions of the Creative Commons Attribution license (http://creativecommons.org/licenses/by/3.0/). 